\title{
High-Rise: \\ la aplicación de los cuatro capitales
}

Alicia Helena Hernández Barba ${ }^{1}$

Gerardo González de las Peñas ${ }^{2}$

https://doi.org/10.36105/stx.2018n1.08

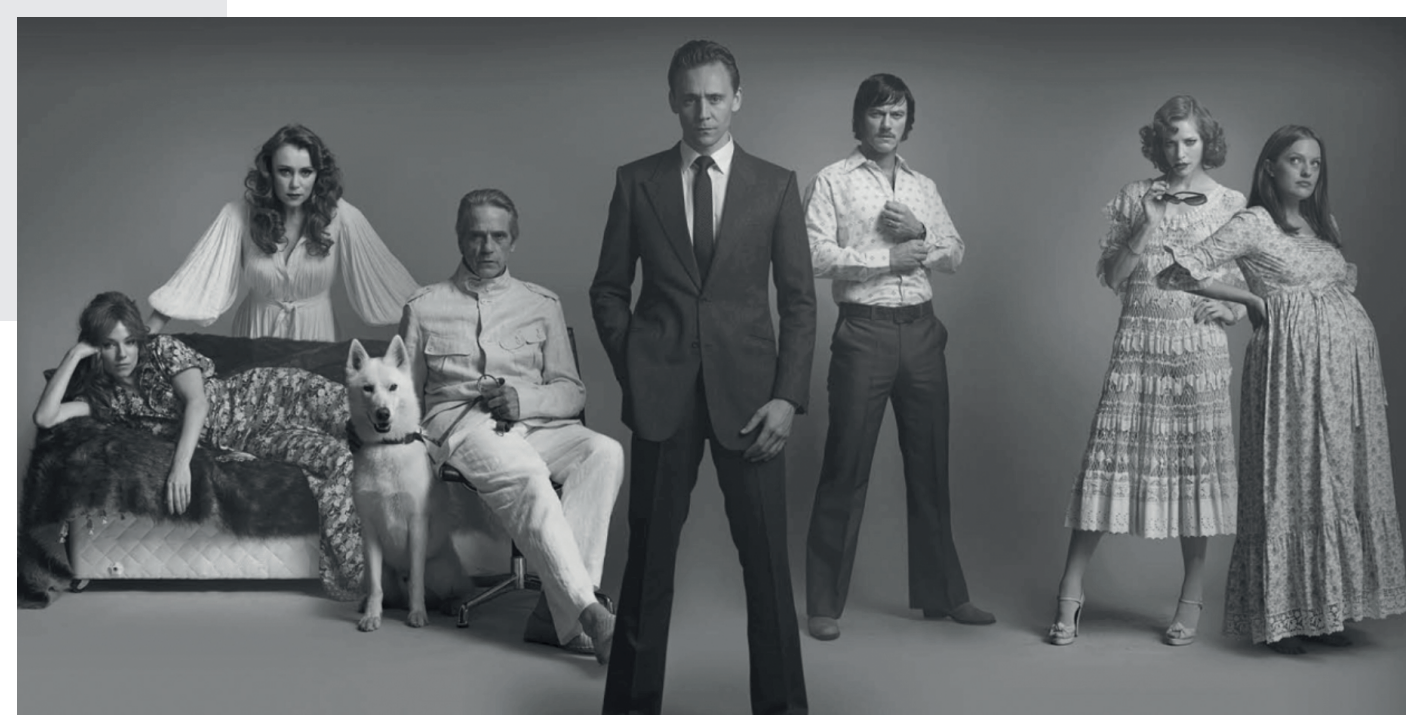

\section{Resumen}

La intención del siguiente artículo es realizar un análisis mediático, para lo cual tomaremos lo propuesto por Dennis McQuail, en una línea científico social, donde el análisis está basado en la aplicación de una teoría que se ve reflejada en el producto audiovisual. En este caso nos decidimos por la teoría de capitales de Pierre Bourdieu, y la aplicaremos en la película High Rise, o El rascacielos, como es conocida en México.

\footnotetext{
1 Licenciada en Comunicación de la Universidad Anáhuac México. 16 años como docente en distintas universidades. Maestra en Educación con especialidad en competencias y candidata a Doctor en Comunicación Aplicada. Coordinadora del área de Cine en la Facultad de Comunicación de la Universidad Anáhuac México. Docente, capacitadora de maestros e investigadora del Centro de Investigación para la Comunicación Aplicada (CICA).alicia.hernandez@anahuac.mx

2 Licenciado en Comunicación de la Universidad Anáhuac México, del área profesional de Publicidad y Mercadotecnia. Tiene gusto y conocimiento de cinematografía. En su proyecto integrador realizó un análisis para generar la campaña de promoción de un festival de cine independiente. gerardinos@hotmail.com
} 
En ella pudimos encontrar reflejados los cuatro capitales: económico, simbólico, social y cultural, de una forma visual y de fácil percepción. Se trata de una película con un guión complicado, donde se utiliza la metáfora para hablar de las clases sociales, que se ven representadas en una estructura vertical dentro de este edificio que a su vez nos habla de esa decadencia y descomposición social, teniendo alusiones a la Revolución Francesa de 1678. En el artículo se analiza cómo estos preceptos fueron utilizados en la adaptación de la novela para la producción de esta película.

\section{Palabras clave}

Rascacielos, clase social, capitales, guión, vestuario.

\section{Introducción}

Nos hemos inclinado por utilizar la propuesta del teórico Dennis McQuail (2010), quien agrupa en cuatro aspectos los análisis que se pueden realizar sobre los contenidos mediáticos: sentido común, operacional, normativo y científico social.

El sentido común se basa en la opinión de las personas. El operacional analiza el mensaje sobre los aspectos de producción, como guion, tomas o movimientos de cámara, fotografía, etcétera. Lo normativo está basado en las regulaciones que se deben aplicar en todo producto mediático. En el aspecto científico social se escoge una teoría como eje de análisis del estudio.

En nuestro caso tomamos esta opción, y elegimos la teoría de los cuatro capitales de Pierre Bourdieu, que se encuentra desarrollada en sus Estudios culturales; los cuatro capitales son el económico, cultural, social y simbólico. A lo que se refiere cada uno de ellos, lo iremos explicando dentro del cuerpo de este artículo.

El producto mediático que decidimos trabajar fue un filme, ya que nos pareció de gran interés generar un análisis cinematográfico. Una vez observada la cinta, encontramos que en cada fotografía, diálogo y personaje se encontraba plasmada la teoría de Bourdieu.

High-Rise se estrenó en 2015. Se trata una adaptación de la novela del mismo nombre escrita por J. G. Ballard en 1975. En ella se expone el caso de un psicólogo, Robert Laing, interpretado por el actor británico Tom Hiddleston, quien se acaba de mudar a un nuevo edificio y debe adaptarse a una nueva construcción social y de jerarquías, que dependen del piso donde viven. Los estereotipos (percepción exagerada y con pocos detalles que se 
tiene de una persona o grupo de personas que comparten ciertas características, cualidades y habilidades, y que buscan justificar o racionalizar una cierta conducta en relación a determinada categoría social) y arquetipos (modelo original que sirve como pauta para imitarlo, reproducirlo o copiarlo, o el prototipo ideal que sirve como ejemplo de perfección de algo) están perfectamente bien definidos y demostrarán, dentro de esta lucha de clases, lo que son capaces de hacer para permanecer en su mismo estatus, o bien, subir de nivel; los personajes se destruirán y tendrán que reconstruirse para poder seguir adelante.

Los personajes, la ambientación y las tomas ayudan a describir la decadencia que están viviendo los residentes de este complejo de departamentos y cómo su vida, que llevan con monotonía, obedece a una organización extrema y lineal que rompe con sus propias estructuras y se vuelve decadente y se desorganiza.

Vemos cómo los personajes se desarrollan y abonan a sus capitales, sobre todo al simbólico y al económico. Pequeñas cosas, como el lugar que ocupa la basura, el supermercado, la alberca, el estacionamiento, el pentbouse y la luz, se vuelven elementos que simbolizan las aspiraciones y modificaciones de sus propios roles. Es el caso de la familia que vive en los pisos inferiores, compuesta por Wilder, el padre, un reportero frustrado que busca darse la gran vida social, y Helen, su esposa y madre de dos hijos, en espera del tercero, que quiere una mejor calidad de vida para sus hijos y está dispuesta a todo con tal de lograrlo.

A continuación se presentará una breve sinopsis de la película para conocer el contexto en el que se aplicará la teoría de Bourdieu.

\section{Selección oficial}

2015 Toronto International Film Festival-Premier mundial

Sinopsis

Higb-Rise. El Dr. Robert Laing (Hiddleston) es el nuevo residente de un lujoso departamento localizado en un rascacielos de alta tecnología, cuya ubicación lo sitúa cerca de la clase alta. Rápidamente se asienta en la vida de la alta sociedad y conoce a los excéntricos inquilinos que habitan el edificio: Charlotte (Miller), una madre soltera bohemia que ocupa el departamento de arriba; Wilder (Evans), un simpático documentalista que vive con su esposa Helen (Moss), que está embarazada, y Mr. Royal (Irons), el enigmático arquitecto que diseñó el edificio. Resignado a las complejas dinámicas sociales que lo rodean, Laing afronta la situación y se convierte en un buen vecino. Sin embargo, las luces se apagan y los 
ascensores no funcionan, el orden social comienza a desmoronarse y el edificio se convierte en un campo de batalla, donde las diferentes clases sociales se enfrentarán.

Higb-Rise es la última película del director británico de culto Ben Wheatley (Kill List, A Field in England) y una ambiciosa adaptación de la novela de J. G. Ballard del mismo nombre. (Magnolia Pictures, 2015).

Los cuatro capitales de Pierre Bourdieu

En Poder, derecho y clases sociales (1983), Bourdieu define el capital como el trabajo acumulado, tanto en forma de materia como en forma interiorizada o incorporada.

El capital hace que los juegos de intercambio de la vida social, en especial de la vida económica, no discurran como simples juegos de azar en los que en todo momento es posible la sorpresa [...] El capital es una fuerza inscrita en la objetividad de las cosas que determina que no todo sea igualmente posible e imposible. La estructura de distribución de los diferentes tipos y subtipos de capital, dada en un momento determinado del tiempo, corresponde a la estructura inmanente del mundo social, esto es, a la totalidad de fuerzas que le son inherentes, y mediante las cuales se determina el funcionamiento duradero de la realidad social y se deciden las oportunidades de éxito de las prácticas. (Bourdieu, 2000, p. 132, 133).

Es decir, el capital acumulado por los individuos determinara el lugar que éstos ocupan en la sociedad.

Las especies de capital, como una buena carta en un juego, son poderes que definen las probabilidades de obtener un beneficio en un campo determinado (de hecho, a cada campo o subcampo le corresponde una especie particular de capital, vigente como poder y como lo que está en juego en ese campo). Por ejemplo, el volumen del capital cultural (lo mismo valdría mutatis mutandis para el capital económico) determina las posibilidades asociadas de beneficio en todos los juegos en que el capital cultural es eficiente, contribuyendo de esta manera a determinar la posición en el espacio social (en la medida en que ésta es determinada por el éxito en el campo cultural). (Bourdieu, 1990, p. 282-283).

Dicho capital puede ser de diversos tipos. De acuerdo con Bourdieu, el capital económico abarca las condiciones materiales de existencia, así como las diferencias sociales expresadas en el consumo de los individuos o grupos sociales. Este tipo de capital es convertible en dinero. Para Bourdieu, el capital social es un:

conjunto de los recursos actuales o potenciales vinculados a la posesión de una red duradera de relaciones más o menos institucionalizadas de interconocimiento e inter-reconocimiento $[\ldots]$ destinadas a la institucionalización o la reproducción de relaciones sociales utilizables directamente, a corto o a largo plazo. (Bourdieu, 1980, p. 83-85). 
Es decir, totalidad de recursos basados en la pertenencia a un grupo. De acuerdo con esto, el valor de capital social poseído por un individuo dependerá de dos factores principalmente: la extensión de la red de conexiones que éste pueda generar y el capital (económico, cultural o simbólico) poseído por aquellas conexiones.

El capital cultural según Bourdieu puede obtenerse a través de tres formas: 1) Estado incorporado: el cual se refiere a la acumulación de cultura, la cual implica un proceso de enseñanza y aprendizaje. Requiere de tiempo y esfuerzo; 2) Estado objetivado: se manifiesta en posesión de bienes culturales tangibles como cuadros, libros, esculturas etc.; 3) Estado institucionalizado: el cual se manifiesta en forma de un título académico.

Finalmente, Bourdieu añade a la lista el capital simbólico, al cual define como las propiedades que parecen inherentes e intrínsecas a la persona, como el prestigio, la reputación, la autoridad, la fama, el crédito, el buen gusto, la notoriedad, la honorabilidad, etc.

La combinación entre los distintos tipos de capital es lo que caracteriza la estructura o composición. Todos ellos son transformables en otros tipos de capitales (Bourdieu, 1997).

Tomamos las características de los cuatro y realizamos un análisis de cada uno de los personajes y cómo desarrollan cada capital. Consideramos que la manera más sencilla es a través de un cuadro donde se expliquen cómo afectan cada uno de ellos. El cuadro se integra por el personaje, el actor que lo representa y los cuatro capitales, datos sobre el análisis general de cada personaje y cómo se manifiestan en cada uno de ellos las vertientes de los diferentes capitales. Con esta descripción podremos entender de qué manera es posible y factible apreciar estos capitales en una forma audiovisual.

TABLA 1

\begin{tabular}{|c|c|c|c|c|c|}
\hline \multicolumn{6}{|c|}{ DRAM ATIS PERSONAJE } \\
\hline \multicolumn{6}{|c|}{ ELCAP ITALEN PIERRE B OURDIEU } \\
\hline PERSONAJE & ACTOR & ECONÓM ICO & CU LTU RAL & $\mathrm{SOClAL}$ & SIM B ÓபCO \\
\hline Laing & $\begin{array}{l}\text { Tom } \\
\text { Hiddleston }\end{array}$ & $\begin{array}{l}\text { Clase media } \\
\text { Cuello blanco } \\
\text { Burgués } \\
\text { Nivel socioeco- } \\
\text { nómico medio } \\
\text { Piso } 25\end{array}$ & $\begin{array}{l}\text { "The self-contained } \\
\text { types like you, thriving } \\
\text { like an advanced } \\
\text { species in the neutral } \\
\text { atmosphere." } \\
\text { Incorporado: culto, } \\
\text { elegante, discreto. } \\
\text { Sabe comportarse en } \\
\text { diferentes situaciones } \\
\text { sociales. }\end{array}$ & $\begin{array}{l}\text { "No sólo es importante } \\
\text { qué conoces, sino a } \\
\text { quién". }\end{array}$ & $\begin{array}{l}\text { Oportunista } \\
\text { Cambia de estatus } \\
\text { social. } \\
\text { Busca sobre todo } \\
\text { pasar inadvertido y } \\
\text { encajar. Evita situa- } \\
\text { ciones que puedan } \\
\text { ser comprometedo- } \\
\text { ras o dañinas. }\end{array}$ \\
\hline
\end{tabular}


Tabla 1. Continuación

\begin{tabular}{|c|c|c|c|c|c|}
\hline PERSONAJE & ACTOR & ECONÓMICO & CU LTU RAL & SOCIAL & SIM B ÓLCO \\
\hline & & & $\begin{array}{l}\text { Objetivado: tiene } \\
\text { bienes culturales, como } \\
\text { libros, discos, pósters } \\
\text { que hacen referencia } \\
\text { a su profesión, sin } \\
\text { embargo, no hacen } \\
\text { alusión a su persona- } \\
\text { lidad. } \\
\text { Institucionalizado: doc- } \\
\text { tor en Psicología. }\end{array}$ & $\begin{array}{l}\text { Alto, ya que posee } \\
\text { una amplia red de } \\
\text { relaciones sociales, } \\
\text { que abarca el espectro } \\
\text { de los diferentes } \\
\text { extractos sociales y al } \\
\text { uso individual de las } \\
\text { oportunidades surgidas } \\
\text { a partir de ello. } \\
\text { Arribista } \\
\text { Oportunista }\end{array}$ & $\begin{array}{l}\text { Prefiere la seguri- } \\
\text { dad a la aventura. } \\
\text { Es realista y con } \\
\text { sentido común, } \\
\text { muy empático y } \\
\text { adolece de falta de } \\
\text { pretensión. }\end{array}$ \\
\hline Wilder & Luke Evans & $\begin{array}{l}\text { Clase baja } \\
\text { Cuello azul } \\
\text { Obrera } \\
\text { Nivel socioeco- } \\
\text { nómico bajo } \\
\text { Piso } 8\end{array}$ & $\begin{array}{l}\text { Rapes "people he isn't } \\
\text { supposed to" } \\
\text { Incorporado: bárbaro, } \\
\text { primitivo, incivilizado, } \\
\text { inculto. } \\
\text { Objetivado: tiene } \\
\text { bienes culturales, como } \\
\text { libros, discos, pósters } \\
\text { que hacen referencia a } \\
\text { su espíritu anárquico } \\
\text { (ejemplo, póster del } \\
\text { Che). } \\
\text { Institucionalizado: } \\
\text { fallido documentalista. }\end{array}$ & $\begin{array}{l}\text { Medio, ya que posee } \\
\text { una amplia red de } \\
\text { relaciones sociales que } \\
\text { abarca el espectro de } \\
\text { los diferentes extractos } \\
\text { sociales; sin embargo, } \\
\text { el uso individual de las } \\
\text { oportunidades surgidas } \\
\text { a partir de ello es bajo, } \\
\text { ya que carece de la } \\
\text { inteligencia y perspi- } \\
\text { cacia para utilizarlas a } \\
\text { su favor. }\end{array}$ & $\begin{array}{l}\text { El Salvaje } \\
\text { Es fanático, radical } \\
\text { y a veces delirante. } \\
\text { Destruye todo } \\
\text { aquello que no } \\
\text { le conviene o no } \\
\text { comprende, para } \\
\text { protegerse de posi- } \\
\text { bles amenazas. } \\
\text { Su talento es la } \\
\text { extravagancia y la } \\
\text { libertad radical. }\end{array}$ \\
\hline Helen & $\begin{array}{l}\text { Elisabeth } \\
\text { Moss }\end{array}$ & $\begin{array}{l}\text { Clase baja } \\
\text { Nivel socioeco- } \\
\text { nómico bajo } \\
\text { Piso } 8\end{array}$ & $\begin{array}{l}\text { Incorporado: } \\
\text { articulada, aguda y } \\
\text { pasiva. } \\
\text { Objetivado: mismo que } \\
\text { Wilder. } \\
\text { Institucionalizado: sin } \\
\text { títulos. }\end{array}$ & $\begin{array}{l}\text { Bajo; los únicos } \\
\text { vínculos relevantes que } \\
\text { posee son con Wilder } \\
\text { y Laing, sin embargo } \\
\text { no consigue cambiar } \\
\text { su situación y continúa } \\
\text { siendo un ama de } \\
\text { casa desesperada y } \\
\text { frustrada. }\end{array}$ & $\begin{array}{l}\text { Ama de casa } \\
\text { Es ingenua y falta } \\
\text { de experiencia. } \\
\text { Quiere sentirse } \\
\text { amada y ser reco- } \\
\text { nocida. } \\
\text { Cae fácilmente en } \\
\text { el martirio y en la } \\
\text { explotación. }\end{array}$ \\
\hline
\end{tabular}


Tabla 1. Continuación

\begin{tabular}{|c|c|c|c|c|c|}
\hline PERSONAJE & ACTOR & ECONÓM ICO & CU LTU RA L & SOCIAL & SIM B Ó UCO \\
\hline Royal & $\begin{array}{l}\text { Jeremy } \\
\text { Irons }\end{array}$ & $\begin{array}{l}\text { Clase alta } \\
\text { Nivel socioeco- } \\
\text { nómico alto. } \\
\text { Piso } 40\end{array}$ & $\begin{array}{l}\text { Incorporado: inteligen- } \\
\text { te, culto, articulado; se } \\
\text { desenvuelve mejor con } \\
\text { sus pares, tiene dificul- } \\
\text { tad para vincularse con } \\
\text { la gente de escasos } \\
\text { recursos. } \\
\text { Objetivado: tiene un } \\
\text { sinnúmero de bienes } \\
\text { culturales como libros, } \\
\text { discos, piezas de arte } \\
\text { que deberían estar en } \\
\text { un museo. } \\
\text { Institucionalizado: } \\
\text { arquitecto. }\end{array}$ & $\begin{array}{l}\text { Medio, ya que posee } \\
\text { una generosa red de } \\
\text { relaciones sociales, } \\
\text { sobre todo entre sus } \\
\text { pares; sin embargo, el } \\
\text { uso individual de las } \\
\text { oportunidades surgidas } \\
\text { a partir de ello es bajo, } \\
\text { ya que no sabe congra- } \\
\text { ciarse con la clase baja } \\
\text { y la clase alta se voltea } \\
\text { en su contra. } \\
\text { Muere en manos de las } \\
\text { mujeres del edificio en } \\
\text { una secuencia similar a } \\
\text { las brujas de Goya. }\end{array}$ & $\begin{array}{l}\text { Arquitecto } \\
\text { Creador } \\
\text { Quiere ser recor- } \\
\text { dado después de } \\
\text { muerto; dejar un } \\
\text { legado que tras- } \\
\text { cienda. } \\
\text { Teme a la medio- } \\
\text { cridad. } \\
\text { No logra cristalizar } \\
\text { su visión. }\end{array}$ \\
\hline Charlotte & $\begin{array}{l}\text { Sienna } \\
\text { Miller }\end{array}$ & $\begin{array}{l}\text { Clase media } \\
\text { Burguesa } \\
\text { Nivel socioeco- } \\
\text { nómico medio } \\
\text { Piso } 26\end{array}$ & $\begin{array}{l}\text { Incorporado: inteli- } \\
\text { gente, articulada, ma- } \\
\text { nipuladora, perspicaz. } \\
\text { Sabe comportarse en } \\
\text { diferentes situaciones } \\
\text { sociales. } \\
\text { Objetivada: tiene bie- } \\
\text { nes sociales diversos, } \\
\text { que le permiten ser } \\
\text { la host de su piso. } \\
\text { Institucionalizado: sin } \\
\text { títulos. }\end{array}$ & $\begin{array}{l}\text { Alto, ya que posee } \\
\text { una amplia red de } \\
\text { relaciones sociales, } \\
\text { que abarca el espectro } \\
\text { de los diferentes } \\
\text { extractos sociales y el } \\
\text { uso individual de las } \\
\text { oportunidades surgidas } \\
\text { a partir de ello. } \\
\text { Arribista } \\
\text { Oportunista } \\
\text { Seductora } \\
\text { Conoce los secretos de } \\
\text { todos. }\end{array}$ & $\begin{array}{l}\text { Amante } \\
\text { Seductora } \\
\text { Cambia de estatus } \\
\text { social. } \\
\text { Utiliza los secretos } \\
\text { de los demás en su } \\
\text { contra. } \\
\text { Encaja en dife- } \\
\text { rentes situaciones } \\
\text { sociales. } \\
\text { Feminista; acaba } \\
\text { en una posición } \\
\text { de poder y logra } \\
\text { vengarse de su } \\
\text { violador }\end{array}$ \\
\hline
\end{tabular}

De la misma manera, presentaremos un gráfico en donde analizaremos y veremos las características de cada los pisos que integran el rascacielos, el espacio como conclusión de que sí es posible poder aplicar y ver cuáles son las características de los cuatro capitales en función del área audiovisual en la película. 
TABLA 2

\begin{tabular}{|l|l|l|}
\hline \multicolumn{1}{|c|}{ FIE STA } & PISO & \multicolumn{1}{c|}{ CA RA CTE RI STICAS } \\
\hline Clase media-alta & 26 & $\begin{array}{l}\text { Host: Charlotte } \\
\text { Fiesta bohemia, aspiracional. } \\
\text { Mezcla de clases sociales. } \\
\text { Estética y música de los años 70. }\end{array}$ \\
\hline Clase alta & 40 & $\begin{array}{l}\text { Host: Royal } \\
\text { El vestuario es de época (siglo XVIII). } \\
\text { Laing: el único vestido de traje y perteneciente a otro extracto social. (Lo corren) } \\
\text { Estética y música barroca, así como de los 70. }\end{array}$ \\
\hline Clase baja & 8 & $\begin{array}{l}\text { Host: Wilder y Helen } \\
\text { Fiesta de cumpleaños infantil. } \\
\text { No hay luz. } \\
\text { Asisten Laing y Toby. } \\
\text { Interrumpen una fiesta de la clase alta en la alberca. }\end{array}$ \\
\hline
\end{tabular}

SOBRE LA PELÍCULA

\section{Sobre J. G. Ballard}

J. G. Ballard (1930-2009) es un autor británico clave en el movimiento de la nueva ola en la ciencia ficción; llegó a ser considerado como uno de los escritores más importantes del siglo XX (Magnolia Pictures, 2015).

La mezcla distópica de la sexualidad, la alienación y tecnología en su escritura hicieron de Ballard una figura prominente en la literatura posmoderna. Entre sus obras más famosas se encuentran The Atrocity Exbibition, The Drowned World, Cocaine Nights, Crash, Empire of the Sun, High-Rise, Super-Cannes y ConcreteIsland.

El particular estilo literario de Ballard dio lugar al adjetivo "ballardian", definido por el Collins English Dictionary (s.f.) como "algo que se asemeja o sugiere las condiciones descritas en las novelas o historias distópicas de J. G. Ballard”.

Su novela semiautobiográfica El imperio del sol fue adaptada al cine por Steven Spielberg en 1984 y protagonizada por Christian Bale. Su controvertido libro Crash fue llevado a la pantalla grande por David Cronenberg y protagonizado por James Spader y Holly Hunter. La cinta se estrenó en el Festival de Cannes en 1996 y ganó el Premio del Jurado (Magnolia Pictures, 2015). 


\section{Ben Wheatley}

Director y guionista inglés, quien ha trabajado tanto en cine como en televisión dirigiendo diversos capítulos de series, tan importantes como Doctor $W b o$, de gran tradición en ese país (Magnolia Pictures, 2015).

Responsable de películas como de Kill List, Sightseers, Down Terrance. Se ha caracterizado por generar contenidos de temática complicada, donde representa los problemas más profundos de los individuos, de la familia y sociedad. Las relaciones personales y de interacción con los otros.

Sus películas han estado en un sinnúmero de festivales independientes, como Sundance y Cannes.

En la película, Ben Wheatley realiza un extraordinario trabajo en los 119 minutos de duración de la cinta. En ella se adaptaron perfectamente los elementos que llevan a sentir los espacios amplios, como el jardín de la terraza que es enorme y nos recuerda los espacios exteriores del palacio de Versalles, y que hacen un contraste con el minimalismo del despacho del arquitecto, que es totalmente limpio y con paredes blancas. A su vez, contrasta con la decoración de su departamento, donde encontramos alfombras, sillones, chimeneas que lo vuelven acogedor; por separado, estos tres escenarios podrían hablarnos de tres lugares diferentes, pero al estar relacionados con los personajes resultan significativos (Magnolia Pictures, 2015).

A continuación presentamos la descripción de los personajes y la descripción para entender mejor el engranaje que tendrán entre ellos.

TABLA 3

\begin{tabular}{|l|l|l|l|l|l|}
\hline \multicolumn{7}{|c|}{ D RAM ATIS P E RSO N AJE S } \\
\hline P E RSO N J E & ACTOR & \multicolumn{1}{|c|}{ RE FE RE N CIA } & A RQ U E TIP O & DE SCRI P CIÓN & A SP E CTO \\
\hline Laing & $\begin{array}{l}\text { Tom } \\
\text { Hiddleston }\end{array}$ & $\begin{array}{l}\text { R. D. Laing, contro- } \\
\text { vertido psicólogo } \\
\text { cuyas teorías sobre las } \\
\text { enfermedades como la } \\
\text { psicosis, estaban ínti- } \\
\text { mamente relacionadas } \\
\text { con el estrés causado } \\
\text { por las demandas de la } \\
\text { sociedad y la familia. }\end{array}$ & Arribista & $\begin{array}{l}\text { El nuevo residen- } \\
\text { te del edificio: } \\
\text { psicólogo y un } \\
\text { codiciado sol- } \\
\text { tero. }\end{array}$ & Refinado y distinguido. \\
Provoca admiración y \\
deseo de ser imitado.
\end{tabular}


Tabla 3. Continuación

\begin{tabular}{|c|c|c|c|c|c|}
\hline Wilder & Luke Evans & $\begin{array}{l}\text { Wilder: no civilizado; } \\
\text { bárbaro, } \\
\text { primitivo, incivilizado, } \\
\text { inculto. }\end{array}$ & $\begin{array}{l}\text { Destructor } \\
\text { Anarquista }\end{array}$ & $\begin{array}{l}\text { Un fallido } \\
\text { documentalista } \\
\text { y depredador } \\
\text { sexual. }\end{array}$ & $\begin{array}{l}\text { Original, imaginativo, } \\
\text { artístico. } \\
\text { Comunica individualidad } \\
\text { ante la vida. }\end{array}$ \\
\hline Helen & $\begin{array}{l}\text { Elisabeth } \\
\text { Moss }\end{array}$ & & $\begin{array}{l}\text { Inocente } \\
\text { Ama de casa } \\
\text { desesperada }\end{array}$ & $\begin{array}{l}\text { La esposa sufrida } \\
\text { y embarazada de } \\
\text { Wilder. }\end{array}$ & $\begin{array}{l}\text { Accesible, sencilla e } \\
\text { informal. } \\
\text { Desarreglada }\end{array}$ \\
\hline Royal & $\begin{array}{l}\text { Jeremy } \\
\text { Irons }\end{array}$ & $\begin{array}{l}\text { Royal: Relativo al rey, } \\
\text { la reina o la realeza; } \\
\text { suntuoso. }\end{array}$ & $\begin{array}{l}\text { Creador } \\
\text { Arquitecto } \\
\text { Gobernador }\end{array}$ & $\begin{array}{l}\text { El ermitaño } \\
\text { arquitecto del } \\
\text { edificio; vive en } \\
\text { el penthouse. }\end{array}$ & $\begin{array}{l}\text { Ropa sobria y útil en } \\
\text { cualquier ocasión. } \\
\text { Comunica una personali- } \\
\text { dad conservadora }\end{array}$ \\
\hline Charlotte & $\begin{array}{l}\text { Sienna } \\
\text { Miller }\end{array}$ & & $\begin{array}{l}\text { Amante } \\
\text { Seductora }\end{array}$ & $\begin{array}{l}\text { Madre soltera } \\
\text { bohemia, seduc- } \\
\text { tora y perspicaz. }\end{array}$ & $\begin{array}{l}\text { Utiliza ropa que le permite } \\
\text { lucir su cuerpo. } \\
\text { Proyecta una personalidad } \\
\text { seductora y atractiva. }\end{array}$ \\
\hline
\end{tabular}

A través de esta descripción comprendemos a los personajes y los podemos relacionar con los cuatro capitales y su desarrollo como parte de la trama; por ejemplo, el caso de Royal, que desde su nombre nos habla de la "realeza". Si se hace una traducción literal de la palabra y se considera el estatus que tiene en la pirámide social, nos habla de que es el arquitecto dueño del rascacielos, tiene el poder de hacer lo que quiera; sin embargo, nadie lo ha visto, saben que existe, pero no lo reconocen. Es una gran metáfora de lo ocurrido con Luis XIV, que prácticamente pudo huir hasta que fue reconocido porque su cara se parecía a la que se encontraba en las monedas.

Wilder, salvaje en español, es el personaje que busca subir de nivel y cuestionar todo lo que se está haciendo en el edificio, además siente que debería tener lo mismo que poseen los vecinos de los pisos superiores, y decide tomarlo a la buena o a la mala. El caos del edificio se vuelve su gran marco para lograr su objetivo.

También encontramos diferentes estereotipos de mujeres, como el caso de Helen y Charlote, que representan distintas mujeres. La primera es madre de dos chicos en espera del tercero. Su vida adquiere sentido en el cuidado de sus hijos, sin embargo tiene la sensación de que si viviera en los pisos superiores su vida sería mejor, tendría más "luz", como hace referencia en la escena donde se asoma por la ventana y en su cara se muestran sombras de los pisos superiores. 
Charlote es la cortesana, la amante del arquitecto, pero no cualquier amante, es la madre del hijo de Royal, tiene beneficios, pero no se le permite la entrada a los pisos superiores. Es el puente entre los pisos inferiores y el penthouse.

Cada piso tiene su significado. Los inferiores son los que están más cerca del suelo, de la realidad, y no tienen mucha vista, que representa las esperanzas o el futuro. Los pisos de en medio tienen balcones; mayores beneficios, como el supermercado, la alberca y el spa, más cercanos, tienen vista a la ciudad, al cielo, espacios para soñar y pensar en un futuro prometedor. Los pisos superiores al 30, donde sólo viven las personas con un poder económico fuerte, tienen balcones más amplios, mayor lujo y se encuentran por encima de todos los otros vecinos. Por último, el penthouse, donde encontramos todo el aire fresco que soñamos e incluso un jardín que recuerda a Versalles, un elevador privado y todos los lujos que se pueden tener.

Con lo anterior se puede concluir que conforme se sube de piso esto representa una mejora social y económica. A continuación presentamos una tabla donde se describen las características encontradas en estos pisos.

TABLA 4

\begin{tabular}{|c|l|}
\hline PISO & \multicolumn{1}{|c|}{ HAB ITANTE S / CARA CTE RI STICAS } \\
\hline 40 & $\begin{array}{l}\text { Penthouse } \\
\text { Elevador privado } \\
\text { Hogar de Royal y su esposa } \\
\text { Hábitat de la clase alta }\end{array}$ \\
\hline 30 & $\begin{array}{l}\text { Spa, alberca y gimnasio } \\
\text { (Acceso clase alta y media alta) }\end{array}$ \\
\hline 26 & $\begin{array}{l}\text { Departamento de Charlotte } \\
\text { Hábitat de la clase media alta }\end{array}$ \\
\hline 25 & $\begin{array}{l}\text { Departamento de Laing } \\
\text { Hábitat de la clase media alta }\end{array}$ \\
\hline 15 & $\begin{array}{l}\text { Supermercado } \\
\text { (Mezcla de clases sociales) }\end{array}$ \\
\hline 8 & $\begin{array}{l}\text { Hogar de Wilder y Helen } \\
\text { Hábitat de la clase baja } \\
\text { Sin luz ni agua } \\
\text { Basura }\end{array}$ \\
\hline
\end{tabular}




\section{Conclusiones}

Hemos realizado un análisis a partir de la descripción de cada uno de los elementos que componen esta película, desde el guion, basado en el libro original, escrito en 1975; el vestuario, el diseño de arte, las actuaciones extraordinarias. El perfecto casting que ayuda al desarrollo de los personajes, su esencia, y el desarrollo y la evolución que atraviesan durante la película.

También es importante mencionar el tributo que hace el director al autor del libro, al mantener intacta la década de los setenta, con todos sus elementos, para poder hacer narrar lo que ocurre dentro del rascacielos.

Después del análisis realizado sobre cada uno de los cuatro capitales de Pierre Bourdieu pudimos notar que la metáfora sobre el desequilibro social se ve reflejada en los personajes, en su vestuario y actitudes, pero sobre todo en su ubicación en los pisos del rascacielos.

\section{Referencias}

Ballard, J. G. (2012). High-Rise: A Novel. Nueva York: Liveright (WW Norton).

Bourdieu, P. (1997). Capital cultural, escuela y espacio social. Madrid, España: Siglo XXI Editores.

Bourdieu, P. (1990) Espacio social y génesis de las clases. En Sociología y cultura. P. Bourdieu. México: Editorial Grijalbo.

Bourdieu, P. (2000) Las formas del capital. Capital económico, capital cultural y capital social. En P. Bourdieu. Poder, derecbo y clases sociales. Bilbao: Editorial Desclée de Brouwer.

Bourdieu, P. (1980). O poder simbólico (pp. 65-73). Lisboa: DIFEL.

Bourdieu, P. (1983). Poder, derecho y clases sociales. Bilbao: Editorial Desclée de Brouwer.

Gordoa, V. (1999). El poder de la imagen pública. México: Edamex.

McQuail, D. (2010) McQuail's mass communication theory. Los Angeles: Sage.

Magnolia Pictures (2015). High-rise; final press notes. Nueva York. Recuperado de http://www.imdb. com/title/tt0462335/

Nichols, S. (1989). Fung y el tarot: un viaje arquetípico. Barcelona: Editorial Kairós.

Wheatley, B. (Director) \& Thomas, J. (Productor) (2015). El rascacielos. [Película]. Irlanda: Hanway Films. 